\title{
The 'Futures' of Queer Children and the Common School Ideal
}

\section{KEVIN MCDONOUGH}

\begin{abstract}
This paper focuses on an especially urgent challenge to the legitimacy of the common school ideal-a challenge that has hardly been addressed within contemporary debates within liberal philosophy of education. The challenge arises from claims to accommodation by queer people and queer communities_claims that are based on notions of queerness and queer identity that are seriously underrepresented within contemporary liberal political and educational theory. The paper articulates a liberal view of personal autonomy that is constituted by a conception of practical reasoning rooted in thick communal experiences. It is argued that common schools concerned with equal concern for the autonomy of all children must attend to the specific communal requirements needed to developing the autonomous practical reasoning of queer children-requirements for what is termed a sense of 'futurity'. Five practical recommendations for common schools are briefly outlined. The paper concludes with some reflections on the divergent and convergent interests of queer theory and liberalism, and considers some possibilities for a partial reconciliation of the two theoretical perspectives.
\end{abstract}

At the most basic level, a 'common school' can be regarded as a school which is open to, and intended for, all students within a given society regardless of their specific differentiating characteristics (Terence McLaughlin, 2003, p. 122).

\section{INTRODUCTION}

A fundamental test of the common school's legitimacy is this: Can the common school ideal, and the liberal political principles that underwrite it, coherently accommodate reasonable and legitimate forms of moral and cultural diversity, especially those forms that have historically been marginalised, discriminated against or excluded? In this paper, I focus on an especially urgent challenge to the legitimacy of the common school ideal-one that has hardly been addressed within contemporary debates within liberal philosophy of education. ${ }^{1}$ This challenge arises from claims 
to accommodation by queer people and queer communities-claims that are based on notions of queerness and queer identity that are seriously underrepresented within contemporary liberal political and educational theory. At its simplest, the question I wish to address is how liberal principles that underwrite the common school ideal are capable, if they are capable at all, of providing a coherent ethical and educational basis for accommodating and recognising queer people and queer identities.

\section{QUEER THEORY MEETS LIBERALISM: FUTURITY, AUTONOMY AND FLOURISHING}

The view that liberal theory and liberal educational institutions cannot adequately accommodate the legitimate claims of queer children (and adults) has recently been advanced by queer theorists who are beginning to critically engage with the arguments of 'mainstream' liberal philosophers of education. A good example of the willingness on the part of queer theorists to engage critically with liberal arguments can be found in recent articles by Cris Mayo (2006a, 2006b), and for that reason her work provides the primary reference point in queer theory for my arguments in this paper.

Perhaps Mayo's deepest concern is that liberalism, and the educational institutions it sponsors, have thus far failed to address, and perhaps cannot address, the fact that 'queer children are denied a sense of futurity' in liberal societies and in public schools (Mayo, 2006a, p. 473). As Mayo puts it, 'For a philosophy and political practice dedicated to interrogating traditions and opening possibilities for innovation, liberalism has been suspiciously unwilling to extend its analysis to sexual freedom, its embrace of autonomy to queer critique, its sense of progression toward new possibilities to queer futurities' (p. 471).

In developing a liberal response to queer theory's concerns, I follow Mayo's usage of the terms 'queer', 'queer identity' and 'queer children'. According to Mayo, 'one reason theorists have turned to using the concept "queer" is to underline the uncertainty and shifts in sexual identities, practices, and communities' that queerness raises for queer people and communities, and for the wider population (p. 469). A number of complexities are worth attending to here. First, 'queerness' refers to more than a person's sexual desire or preferred sexual behaviour. For example, it implies a certain orientation to the ways in which one's gay, lesbian, bisexual or transgendered identity unsettles and 'disrupts' dominant heterosexual norms, roles, laws and communities. Thus, there is an overtly political element to the term that is lacking or less prominent in terms like 'homosexual' or 'sexual orientation'. This political element is explicitly oppositional with respect to the dominance and exclusiveness of heterosexual norms and assumptions in law, policy and public institutions.

The term 'queer identity' also suggests an affiliation with self-identified queer communities. Not all homosexual people will accept queer affiliations in this sense, though queer theorists will argue that queerness 
still applies in a more limited sense to all gay, lesbian, bisexual and transgendered people, even in the absence of felt affiliation. For example, some people with homosexual desires may live their lives in heterosexual marriages. And some homosexual couples will live according to roles and values that seamlessly merge with those of many heterosexual families; and they may have little interest in highlighting or drawing attention to the main difference between them and their heterosexual neighbours- the fact that both partners in the relationship share the same gender. Nevertheless, as queer theorists will point out, that difference may not be missed and may not be accepted by the heterosexual neighbours and citizens with whom gay and lesbian couples must share a society and polis; and the laws and political policies of the liberal state may not include them as equal citizens in many respects. In this way, the concept of 'queerness' captures a sort of social 'rupture' that is present even when homosexuals reject the queer identity label.

Finally, and most importantly, the term 'queer children' refers to children whose sexual identity is not simply 'in formation' as are the sexual identities of all children, but children whose identities depend upon social categories that are as yet not widely understood or recognised, and often are excluded by liberal law, or within public political and social discourses within liberal societies. Because these identities are poorly understood, because they are viewed with considerable 'animus' by heterosexual citizens, and because their sexual differences are not assigned equal value within liberal law and politics, Mayo argues that queer children are 'barely recognizable', particularly in public schools (p. 469).

I am particularly concerned with issues having to do with the 'recognition' and accommodation of queer children in common schools. However, it might seem that the preceding discussion of queerness makes the notion of 'queer children' and their recognition in schools a problematic one. If children's identities are still developing into forms that are poorly understood, in part because those forms are still emerging and changing, then it might seem premature to speak of the need to support and recognise those identities in schools. For one thing, it is not clear what is being supported and recognised; and as such it may be that the intention to 'recognise' and 'support' gets distorted into forms that are both anti-liberal and against the best interests of queer children. For example, if identities are poorly understood, then the danger may arise that schools will socialise children into pre-existing moulds based on educators' distorted and inauthentic conception of what a queer identity should be, rather than leaving children free to choose and endorse their own conceptions of queerness through an examination of how queer people actually might live worthwhile lives. ${ }^{2}$ In addition to impeding children's autonomy, this educational approach would constitute a damaging form of identity misrecognition, since it would change and distort queer identities (perhaps unintentionally), rather than recognise them.

Here I want to stress two points. First, the demand for queer recognition need not assume that we know beforehand precisely what forms of queer social identity forms are being recognised; nor does it require that we be 
able to identify exactly which children are 'queer children' and which ones are not, so that we can on that basis 'recognise' them accordingly. Rather, it assumes that some children will discover at some point in their development-perhaps not until they are adults-that they cannot live well as heterosexuals. Furthermore, it is precisely because we cannot pick out beforehand which children these will be that all children require exposure to alternative models of identity, including queer models, upon which to base their developing individual sexual identities (for a compatible view see, for example, Brighouse, 2000, pp. 74-5; Brighouse, 2006, pp. 17-18).

The second point I want to emphasise is that the demand for queer recognition need not assume that the boundaries between queer children and heterosexual or 'straight' children are crystal clear and absolutely fixed. Again, the main assumption underlying the demand for queer recognition in common schools is that some children will find that their identities simply cannot 'synch up' comfortably with conceptions of good living that heterosexuality provides. For these children, sexual identity will not be a matter of choice, or it will be a matter of limited choice because it will exclude heterosexual options while remaining open to a variety of alternatives. But this is compatible with a wide range of (necessarily speculative) views about the ultimate origins and sources of sexuality and sexual difference. It may be, for example, that for many children the discovery that their queer identity is not a matter of choice is a complex matter of socialisation and genetic endowment. For others, the question of whether to live as a heterosexual or as a homosexual or as a bisexual person may seem more open-ended. It may also be that, for some, heterosexuality and homosexuality are 'phases' through which one passes. This is not objectionable speculation from the liberal point of view so long as we acknowledge both possible tracks along which the 'phase' might constitute a moment of progression. That is, it must be acknowledged that one child might develop in such a way such that her heterosexuality is a phase in an otherwise homosexual life; while a different child could develop in such a way that homosexuality is a phase in a life whose future is heterosexual (Reiss, 1997, p. 348).

The significance of these two points is this. Although we may lack certainty about which children will turn out to be 'queer' and although there may be differing views about how fixed (or fluid) we should interpret sexual identities to be, some children will turn out to reject heterosexual ways of life and heterosexual identities, and in some cases this will not be a matter of choice at all; in other cases it will be a matter of choice only among various non-heterosexual identities; in still other cases there may be a choice to alter one's sexuality in order to adjust it to new circumstances and new self-knowledge. Thus, uncertainty and disagreement about how to draw the line between queer and non-queer identities does not obviate the need for an exploration of why and how liberal common schools might accommodate queer identities. Such an elaboration is needed in order to ensure that children have educational opportunities that include the possibility of a 'queer future'. 


\section{LIBERAL AUTONOMY AND 'FUTURITY'}

What does all this have to do with liberal education and the recognition of queerness in the common school? The connections to liberalism may already seem quite clear, at least in outline-especially the connection to liberal concerns about democratic citizenship and personal autonomy. But does pursuing these educational aims require something that we might want to call the 'recognition' of queerness and queer identities in common schools? to address this question, I begin with John White's recent comments:

A core liberal value is personal autonomy. An autonomous person is one who determines how he or she should live according to their own, unpressured, picture of a worthwhile life. But autonomy on its own is not enough. A tyrant might also value this, but only for himself, just as a certain sort of elitist might think autonomy fine for the upper classes to which she belongs, but not for the common people. A liberal makes no such discriminations among persons: personal autonomy is a good applicable to all. Equality of consideration is, therefore, a second core liberal value (White, 2003, p. 147).

The connection White emphasises between autonomy and equal consideration is crucially important, since it highlight's liberalism's concern to extend autonomy to individuals from historically excluded and marginalised groups. Liberal schooling is, of course, seen as a vital instrument for extending autonomy in this way. It follows from this claim that the autonomy of queer children is as valuable and important a political and educational concern of the liberal state as that of any other child. It also follows that liberal education cannot legitimately 'educate children away from queer futures' any more than it can educate children 'away from heterosexual futures' (Mayo, 2006a, p. 473). These are matters for autonomous choice, and liberal education must treat them as such.

\section{EQUAL CONSIDERATION: WHAT IS THE DIFFERENCE BETWEEN SPELUNKING AND QUEERNESS?}

Why, though, does equal consideration of autonomy require explicit recognition of queer identities? In order to autonomously choose a life as a spelunker, ${ }^{3}$ centred on the goods and skills of spelunking, I need not have been familiarised with the activity of spelunking itself until adulthood. Certain cognitive and affective capacities developed as a child, in relation to an examination of other ways of life may have prepared me sufficiently to evaluate this and other ways of life, that I did not become familiar with until after my schooling had ended. The question arises, then, why does promoting the autonomy of queer children require that we familiarise children with queer ways of life and 'queer identities' prior to adulthood?

Here I ask this question without considering the school's role. What I mean to ask, simply, is why we might think that children's autonomy 
depends on their becoming familiar with specifically queer roles and queer communities and queer identities? Why are not generic capacities for critical thinking and sympathetic imagination for alternative ways of life sufficient? The reason it is important to answer these questions is that if the failure explicitly to expose children to queer ways of life does not affect the development of their autonomy, then we have no reason to suppose that a concern for children's autonomy requires the school to recognise queer identities. But if queer children's autonomy does depend on actual engagement with queer options, then there exists a compelling prima facie reason for the common school to facilitate such engagement. I shall argue that the compelling prima facie reason does exist, and that it entails a form of 'recognition' for queerness in common schools.

Alasdair MacIntyre's comments on how the ability to imagine different futures is connected to the capacity for practical reasoning are extremely helpful here. MacIntyre is interested in particular in understanding the various dimensions of 'the child's transition from dependent infancy to the agency of an independent practical reasoner' (MacIntyre, 1999, p. 72). One such dimension, he notes, is the acquisition of the ability to imagine 'different possible futures for me'. The full passage in which this comment occurs is worth quoting:

How we structure our understanding of the future depends in part of course on the established use of clocks, calendars, and modes of scheduling of the culture in which we find ourselves. But as a practical reasoner I have to be able to imagine different possible futures for me, to imagine myself moving forward from the starting point of the present in different directions. For different or alternative futures present me with different and alternative sets of goods to be achieved, with different possible modes of flourishing. And it is important that I should be able to envisage both nearer and more distant futures and to attach possibilities, even if only in a rough and ready way, to the future results of acting in one way rather than another. For this both knowledge and imagination are necessary (MacIntyre, 1999, pp. 74-5).

MacIntyre here is writing in the context of a discussion of how disabled children might be subjected to 'too constrained and impoverished a view of future possibilities' ( $p .75$ ) in what might be called 'able-normative' societies. ${ }^{4}$ Importantly, according to MacIntyre's account, the impoverishment of imagination about disabled children's 'future possibilities' is not primarily a characteristic of the disabled individual (though it obviously affects the disabled more profoundly than it does the abled). Rather, it is a characteristic primarily of 'the groups of which [the disabled child] is a member'. To illustrate: one example of the way in which ablenormativity exerts a withering pressure on the 'imagined possible futures' of disabled children lies in what Hans Reinders calls 'the presumption of suffering' of the disabled and those who care for them (Reinders, 2000, ch. 10). As MacIntyre notes, something like this presumption is often attached to characteristics such as "blindness, deafness, deformed and injured limbs, and the like ...'; and because this presumption suffuses 
communal norms, institutions, modes of relationship, etc., it and other similarly harmful presumptions "exclude the sufferer from more than a very, very limited set of possibilities. And this has often been treated as if it were a fact of nature' (MacIntyre, 1999, p. 75).

What MacIntyre's discussion highlights, most importantly, is how communal attitudes, norms and relationships help to 'structure our understanding of the future' at the level of individual development, upbringing and education. Furthermore, important elements of communal life that structure the development (or lack of development) of skills of independent practical reasoning are mutually reinforcing sets of rules (laws), virtues and practices. Without sustained and engaged exposure to these elements of a community in 'good order' then the capacities for independent practical reasoning can develop only inadequately, in ways that diminish our individual and communal 'view of future possibilities' (p. 85).

These reflections on the ways in which the agency of disabled people is dependent on (in part) communally structured 'visions of future possibility' apply similarly to the case of queer children. If the communities of which children are a part (here I do not just mean those children who turn out to be queer, but all children) fail to include expansive visions of queer possibilities, then the ability of queer children (i.e. those who turn out to be unable to live their lives as heterosexuals) to develop into independent practical reasoners will be constrained to the extent that they will be unable to link up their reasoning to realistic and expansive 'imagined futures' involving valuable and worthwhile queer roles, communities and identities. Relatedly, they will not be able acquire sufficient knowledge of the goods those communities afford their members, and they will be unable to achieve a sufficiently vivid sense of the virtues, practices and rules that provide group members with a meaningful understanding of what their respective intermediate and longterm alternative future possibilities might consist in.

The problem in the case of queer children is not just that their communities lack a sufficiently expansive range of queer futures. Rather, the problem is also that those communities may actively to foreclose queer possibilities as children's capacities of independent practical reasoning are developing. These forces of foreclosure are even more powerful in the case of queer children (arguably) than they are in the case of disabled children. And one reason for this has to do with the differences of family relationship that structure queer children's futures differently from those of other children, including children with disabilities.

\section{QUEER CHILDREN AND THE FAMILY}

In societies where heterosexual roles and norms are dominant in politics, law and civil society, numerous socially acceptable and approved pathways for heterosexual identity development are available for children to examine and choose from. Furthermore, families are likely to support and encourage children's access to and familiarity with at least some if not 
many of these different social contexts so as to increase their opportunities and to expand their imaginative horizons. At the very least, they are not likely to restrict children's access to heterosexual roles and communities simply because those roles are heterosexual ones. Furthermore, heterosexual children can usually count on a good deal of parental love, support and care as they grow up; or at least their sexuality does not usually present the prospect of the parental withdrawal or rejection as it may for queer children. At any rate, the development of a capacity for personal autonomy and well-being is not typically threatened for heterosexual children due to the lack of available or valuable heterosexual role models, communities, etc., though the development of these same capacities may be threatened for just these reasons in the case of queer children.

Queer roles and communities are also available within liberal civil societies, and as such they are potentially accessible to queer children and queer youth. But the availability and accessibility in this case is comparatively thin and restricted, especially when it comes to children. First, queer communities may be few and far between-in part because those adult forms of community tend to be concentrated in certain areas of large urban centres (Levy, 2005, p. 183). Furthermore, queer communities are likely to be subject to strong social and parental disapproval; and thus exposure and access to these communities for young people will often be viewed as harmful and dangerous, rather than as providing a rich and textured social fabric for positive identity formation. Finally, queer children are more likely than heterosexual children to be members of families that do not favour their sexual identity and that thus seek to change it, impede it or at the very least neglect its development and flourishing. Problematically, then, on the one hand, queer and 'proto-queer' children will often find that their emerging sense of personal identity fits uncomfortably, if at all, into the socially accepted 'heteronormative' pathways. On the other hand, the adults who have the power over and responsibility for queer children's sense of future possibilities are unlikely to facilitate access to queer communities that might support a more expansive sense of future queer possibilities.

At the same time, the extra-familial communities of which queer children are members-families, neighbourhoods, churches, local community organisations, etc.-will likely reinforce a diminished sense of future queer possibilities, rather than expand them. This will not always be due to 'animus' towards queerness or queer people. Rather, it may result from the lack of fit between social categories available for identity recognition, on the one hand, and queer children's complex selfunderstandings, on the other hand. Thus, for example, a child's parents may be scrupulously committed to liberal principles of non-discrimination while also expressing disapproval and confusion at their son's periodic and (to the parents) unpredictable flirtations with cross-gender dressing. As this example illustrates, heterosexual families and communities will often lack concrete, phenomenological understandings of how people who identify inconsistently or not at all with established gender categories negotiate their complex self-understandings. As such, their child's self-understanding is 
likely to exist in part in the interstices of his family's or his local community's accepted social identity categories. And thus even the sympathetic heterosexual family or community may be ill-equipped to help a queer child make the transition from the confusions and dislocation associated with interstitial self-understanding to socially accepted and meaningful identity. Thus, queer children who grow up in heterosexual families and communities will likely find themselves in social contexts that provide too limited a set of experiences to 'navigate the complexity and possibility of language', experience and meaning they need in order to explore 'future possibilities' (Mayo, 2006b, p. 43). This also constitutes an important difference between queer children and heterosexual children; hetero-sexual children are far more likely to have substantial exposure to caring communities and families that provide expansive and meaningful visions of their future possibilities.

These complexities of sexuality can and do create considerable confusion and distortion about queer sexual identities, both from the perspective of queer children themselves and on the part of non-queer people whose responses to and interpretations of queerness, or perhaps absence of response to and lack of interpretation of queerness, play an important role in the shaping of queer identities. These confusions are likely to have harmful effects on queer children's identity formationon their autonomous flourishing. Martha Nussbaum neatly summarises the complex and various ways in which processes of misrecognition and lack of recognition toward queer people can cause harm: 'Like E.M. Forster's character Maurice, many gay and lesbian [and, Mayo would add, bisexual and transgendered people] seem indistinguishable from nongay people - or, rather, distinguishable only by the experience of discovering that what they want is socially unacceptable' (Nussbaum, 2000, p. 232).

Unlike that of heterosexual children, whether they come from religious or non-religious families, the experience of growing up in a heteronormatively constituted society may be an experience of pervasive hostility and harm. It may also be an experience of growing up in families and communities that lack expansive possibilities for 'queer futures'; and it is likely to be an experience that insulates one from or bars access to more friendly and hospitable queer communities and social contexts. But if MacIntyre is right, as he surely is, that individual agency and flourishing depend on 'knowledge and imagination' about one's future possibilities and that this must be developed through concrete, phenomenologically rich encounters with real communities, stories and identities, then the problems facing queer children seem especially severe. The fundamental problem may not be that queer children have fewer opportunities than heterosexual children to develop a sense of autonomous flourishing. The problem may be that queer children's education and upbringing provides so little exposure to the material conditions of individual agency and practical reasoning about future possibilities that queer lack any significant opportunities for flourishing at all. (For a different but compatible argument, see Brighouse, 2000, p. 73.) This point highlights 
the need for children to have access to actual queer communities and raises the question of what role the common school might play.

Here we can return to the example of the hypothetical autonomous spelunker that began this discussion. The autonomous adult can presumably choose spelunking as a way of life, without having been exposed to that way of life in his upbringing or education, because two important conditions are met. First, spelunking is a way of life that is available within a social sub-community whose practices, rules and virtues are practised and taught in such a way that I can learn them if exposed to them. Second, my upbringing and education as an independent practical reasoner has not already foreclosed spelunking as an option for me by the time I am exposed to it. That option is 'open' as a future possibility (in this case, the very near future) because it is continuous with and unimpeded by what I have learned as a developing independent practical reasoner up until this point. My society is not pervasively and intensely 'antispelunking', although spelunking is regarded by most members of my community as an exotic and eccentric way of life. And the skills needed for spelunking mesh rather smoothly with the norms, virtues and practices that I have learned in prior stages of my education and development. There are no serious tensions or conflicts, and numerous areas of compatibility and mutual reinforcement between my past identity incarnations (which were once future possibilities as well) and my current 'possible future'-spelunking.

But for many queer children, neither of these conditions can be taken for granted at the outset. And as a result, the task of choosing queer options as adults is likely to be sharply discontinuous with their development as 'practical reasoners', rather than continuous as in the case of the autonomous spelunker. The point I want to stress is just this. That the 'transition from dependent infant to independent practical reasoner' that MacIntyre speaks of requires a certain sort of educational community-a community that children lack in the home or in most locally available groups. Furthermore, independent practical reasoning is constitutive of autonomy. The capacity for autonomy, like the capacity for independent practical reasoning, cannot be based on either wishful thinking based on highly abstract fantasies, or by a restricted imagination based on a limited range of options that excludes many worthwhile possibilities. As such, queer children require exposure to queer communities that provide expansive visions of future possibilities as queer people.

\section{LIBERALISM, THE COMMON SCHOOL IDEAL AND QUEER FUTURES}

In the preceding section I articulated and defended three interlocking claims. First, the development of personal autonomy depends upon an upbringing and education that attends to the conditions necessary for developing and exercising certain capacities of practical reasoning. Second, these capacities of practical reasoning are essential for children to have a vision of possible 'queer futures'. Third, developing these 
capacities of reasoning depends in part on children developing a reasonably thick familiarity with and understanding of actual queer lives and queer communities.

These conclusions suggest some relatively straightforward practical recommendations for the recognition of queerness in the common school. In this section, I would like to briefly address five areas of concern.

First, common schools would need to make serious and sustained attempts to address issues of what seems to be pervasive and persistent violence, bullying and other forms of harassment against queer children in schools. In the US, schools such as the Harvey Milk School in New York City have been established specifically for gay, lesbian and transgendered kids. These schools are partially funded by public money; and the use of public funds is justified in part because these schools are a response to the widespread violence and emotional harm that queer children experience in public schools, in their families and in the wider society (Dennis and Harlow, 1986; see also Mayo, 2006a). ${ }^{5}$ As D.L. Dennis and R.E. Harlow explain, the students in schools such as the Harvey Milk School have often been subjected to violence at the hands of other students and teachers. Furthermore, this abuse is sometimes tacitly endorsed by school administrators who refuse to extend protection to queer students even when they become aware that abuse is occurring, and even when they are aware of which specific individuals are committing the abuse (Dennis and Harlow, 1986, pp. 446-456). Mayo emphasises throughout her paper the multiple and complex ways in which 'animus' against queers might manifest itself in liberal societies and in common schools, and she emphasises the fact that merely adopting official policies of anti-discrimination-for example, speech codes or anti-bullying policies-does not sufficiently address the ways in which discriminatory and violent treatment toward queer students can persist in the presence of such policies, since teachers, administrators and students often fail to recognise such treatment when it occurs; and they may recognise it but nonetheless tolerate it or overlook it when queer students are the target. Where deep-seated animus towards queerness exists, individuals will find creative and sometimes hard-to-identify ways of rationalising and obscuring officially prohibited discrimination and violence. Certainly, ensuring the psychological, emotional and physical well-being of children is a precondition of their developing capacities of autonomous practical reasoning, if anything is.

A second area that requires attention is the curriculum. In order to develop realistic and valuable conception of possible queer futures, children would need detailed and rich examples of queer role models. This might include narratives (historical and fictional) of gay, lesbian and transgendered people that provide a sense of the fullness of their lives. These stories would also need to be incorporated into the curriculum not as tokenistic 'special features' that highlight the eccentricity or exotic nature of queer lives and communities. They would need to be incorporated seamlessly as part of children's educational induction into the complex and multi-faceted, cosmopolitan cultural context of liberaldemocratic societies. Narratives and other cultural products including 
queer elements would need to address issues not merely to do with the 'different' sexual behaviour and sexual desires of gay, lesbian and transgendered people, but also concerning the ways in which their queerness has affected the social, personal, economic and political dimensions of their lives. Attention would need to be given to the ways in which contemporary liberal societies have broached or failed to broach issues of queer oppression and discrimination, and also the ways in which anti-discriminatory legal and political policies address certain aspects of inequality while leaving other aspects of social life unchanged, at least in the short term, as it pertains to the construction and treatment of queer people. It would also need to address the ways in which laws that incorporate heterosexual norms affect both personal and political aspects of life for queer individuals and queer communities.

A third important area of concern is teacher training and hiring practices. Teachers in the common school would need to be knowledgeable about queer life and also be disposed to treat the complex nature of queerness (e.g., in its political, legal, social and personal dimensions) both generously and critically. This is necessary in order to provide children with a realistic picture of what possible queer lives might involve. Relatedly, it is necessary for providing children with either an excessively discouraging picture of the struggles against oppression that such lives often entail, or an excessively unrealistic and fantastic picture of the goods and values that can be derived from such a life. In order to cultivate the capacity for personal autonomy rooted in concrete abilities of practical reasoning, the aim should be to provide a richly concrete, nuanced and detailed, future-oriented sense of what such lives involve. In this way, attempts to attract queer teachers for teacher education programmes, and for public schools, should be included as policy priorities for the common school. And all teachers should be provided with training that would equip them to undertake competently the tasks outlined above.

Furthermore, and fourth, attention should be given to the fact that school officials and school boards are not always, to say the least, supportive of teachers like those described in the preceding paragraph (Reiss, 1997, p. 350). And so in addition to broadly based, sometimes legally imposed, policies of anti-discrimination based on 'sexual orientation', some serious attempts must be made to ensure that official policies are applied in such a fashion as to take account of the manner in which queer children may be discriminated against in 'hidden' or at least ignored ways within the textured, complex social life of school communities. Here, MacIntyre's point about the complex and mutually reinforcing relationships of laws (or rules, such as speech codes and the like), practices and virtues within communal life apply with some force to school communities.

Fifth, and finally, attempts to address issues of recognition and accommodation of queerness and queer identities must address in some way the role that specifically queer communities might play in children's education. As Mayo puts it, 'because liberal theorists consider levels of 
civic engagement to move from family to state, they miss the place of subcommunities and social movements in shaping who youth may become and how they may arrange their lives' (Mayo, 2006a, p. 484). Here the role that state-supported common schools might play is limited but still significant. Common schools cannot simulate or emulate queer subcommunities; nor can they adopt queer communal values as 'constitutive' of the school community. Doing so would violate liberal commitments to inclusiveness and equal consideration. Nevertheless, common schools might seek to find creative ways to foster links and interactions with queer communities. Where possible, this might be done through field trips, guest speakers and perhaps consultations with queer activists regarding the inclusion of queer issues within the school curriculum. Where actual interaction is impossible, due to geographical concerns for example, virtual interaction is possible through web-based learning models. In any case, children's awareness of and familiarity with such communities will be an important part of their education, especially as they make the transition from family and school-based lives to lives of greater independence from those institutions.

\section{CONCLUSION: QUEER THEORY AND LIBERALISM-IS A CIVIL UNION POSSIBLE?}

In seeking to advance the aims of queer liberation, liberalism is often the favoured target of queer critique. This is understandable and sometimes appropriate, especially when the liberalism they challenge is that of liberal realpolitik and of existing liberal educational practices and institutions. Nevertheless, my general conclusion in this paper has been that liberal principles of justice and their educational correlates need not stand in the way of political and educational reforms that significantly accommodate queer recognition in public schools. Moreover, I have tried to show that liberal principles can help to advance the aims of queer recognition more fully than is commonly acknowledged, by either liberal or queer theorists. In particular, I have tried to illuminate some promising routes for extending liberal recognition to queer children and queer communities within public schools.

Nevertheless, it is also important to acknowledge that queer theory and liberalism are to some extent at least embarked on divergent projects. Liberalism is a political theory that seeks to define more clearly the limits of state power over individual lives and seeks to clarify the sorts of educational practices that an appropriately constrained state needs in order to maintain its legitimacy in the eyes of its citizens, and in order to uphold justice within its borders. The constraints that the liberal state must respect include, most importantly, those that arise from social facts of cultural and moral diversity. And the educational practices needed for ensuring legitimacy and justice in a liberal state are deeply shaped by these same facts. Queer theory is not similarly constrained. It is, in part, a theoretical manifestation of a social movement aimed primarily at advancing the 
interests of queer people. In doing so, it is, according to Mayo, 'essentially a movement that disrupts norms'; and queer theory may emphasise and encourage these disruptions without necessarily paying much attention to how liberal norms and values might be reinterpreted in light of the new circumstances and considerations raised by queerness (Mayo, 2006a, p. 472).

The moral constraints constitutive of liberal politics place limits on the extent to which the liberal state can influence the shaping of a child's identity. But they also must impose limits on the authority of cultural, sexual, religious and other sub-communities to shape children's moral commitments and identity. Importantly, the best answers to the question of what these limits should be are not permanently fixed (Feinberg and McDonough, 2003, p. 9). The best answers will change, in part due to changes in understandings about what sorts of identities and commitments are compatible with liberal commitments of equal consideration, tolerance and mutual respect among the morally diverse citizens who comprise liberal societies. To that extent, liberal philosophers of education should seek to respond to the 'normative disruptions' emphasised by queer theory. Liberal philosophy of education should seek to clarify what the best account of those limits is now, in present conditions; but it also seeks to determine what prospects exist for maximising the individual autonomy of all citizens when present social, legal and political conditions illegitimately restrict it.

But the divergences between queer theory and liberalism should not be overemphasised. Significantly, as Mayo herself indicates, queer theorists and advocates are 'often indebted to liberal theory for their general normative commitments' (Mayo, 2006a, p. 472). These debts may be implicit or they may be explicitly acknowledged. But the project of interpreting the limits of liberal norms and the project of advancing queer interests are in any case unlikely to track each other perfectly. The task I have been engaged with in this paper is to see if progress can be made in understanding the extent to which broadly liberal political, moral and educational commitments can be aligned more snugly with a wider, more diverse set of social practices-in particular, practices that are congenial to queer people and to the flourishing of queer children.

I do not know if the forms of educational recognition and accommodation I have recommended in this paper will be sufficiently robust to satisfy the concerns of queer theorists and activists. If they are not, then it may be that my arguments in this paper are wrong and queer theorists like Cris Mayo are right when they argue that liberalism cannot adequately address the educational concerns that queerness raises. But it may also be that queer advocates, like advocates of all the various sub-communities within liberal societies, need to adjust their expectations of what liberalism, as a political theory, can be expected to accomplish in the name of any particular group and its members. However that may be, my hope is that the arguments and ideas in this paper will contribute to an ongoing dialogue that will teach us how common schools might better serve the interests of queer citizens. ${ }^{6}$ 
Correspondence: Kevin McDonough, Department of Integrated Studies in Education, Faculty of Education, McGill University, Montreal, Quebec, H2V 4J5, Canada.

E-mail: kevin.mcdonough@mcgill.ca

\section{NOTES}

1. Some more or less liberally minded educational theorists have addressed issues of teaching about homosexuality as a controversial moral issue (Callan, 2000; Halstead and Lewicka, 1998; Reiss, 1997). However, issues of queer identity have not been discussed in any sustained way in the recent voluminous literature on issues at the intersection of liberalism, cultural identity and education. One notable exception is McKay (1998). Alexander McKay's discussion draws heavily on John Rawls in developing his arguments on sexuality education, but rather than treating sexuality in terms of cultural and identity diversity, he treats these issues as centrally involving ideological pluralism.

2. Thanks to Mark Halstead for helping me to clarify this point.

3. That is, a caver or speliologist.

4. The admittedly awkward label 'able-normative' is mine, not MacIntyre's. I use it simply to highlight the parallel with Mayo's 'heteronormative'.

5. The need for separate schools for queer students is surely regrettable, especially when it is an emergency response to violence and bullying. But if such extreme measures are in some cases the only feasible option, then public funding should at least be sufficient to provide an adequate education. According to Dennis and Harlow, 'The Harvey Milk School is essentially a one-room schoolhouse, staffed only by one full-time and one half-time teacher. The New York City Board of Education pays their salaries ... but all other expenses of the school ... must be paid for [by private fund raising efforts]' (Dennis and Harlow, 1986, p. 455).

6. Mark Halstead and Paul Standish were exceptionally gracious editors of this paper. Both of them provided critical comments, late in the day, on an earlier draft. Without their help, for which I am very grateful, I could not have finished this paper in time to have it included in this special issue dedicated to Terry McLaughlin. I have also benefited a great deal from Liz Airton's insights on queer theory. It has been a delight to learn from her in our numerous conversations over the past few months. Of course, I am solely responsible for any errors contained herein.

\section{REFERENCES}

Brighouse, H. (2000) School Choice and Social Justice (Oxford, Oxford University Press).

Brighouse, H. (2006) On Education (New York, Routledge).

Callan, E. (2000) Discrimination and Religious Education, in: W. Kymlicka and W. Norman (eds) Citizenship in Diverse Societies (Oxford, Oxford University Press).

Dennis, D. I. and Harlow, R. E. (1986) Gay Youth and the Right to Education, Yale Law Review, 89.2, pp. 431-479.

Feinberg, W. and McDonough, K. (2003) Liberalism and the Dilemma of Public Education in Multicultural Societies, in: K. McDonough and W. Feinberg (eds), Citizenship and Education in Liberal-Democratic Societies: Teaching for Cosmopolitan Values and Collective Identities (Oxford, Oxford University Press), pp. 1-19.

Halstead, M. and Lewicka, K. (1998) Should Homosexuality be Taught as an Acceptable Alternative Lifestyle? A Muslim Perspective, Cambridge Journal of Education, 28.1, pp. 4964.

Levy, J. (2005) Sexual Orientation, Exit, and Refuge, in: A. Eisenberg and J. Spinner-Halev (eds), Minorities within Minorities: Equality, Rights, and Diversity (Cambridge, Cambridge University Press).

McKay, A. (1998) Sexual Ideology and Schooling: Towards Democratic Sexuality Education (New York, SUNY). 
McLaughlin, T. H. (2003) The Burdens and Dilemmas of Common Schooling, in: K. McDonough and W. Feinberg (eds), Citizenship and Education in Liberal-Democratic Societies: Teaching for Cosmopolitan Values and Collective Identities (Oxford, Oxford University Press), pp. 121156.

MacIntyre, A. (1999) Dependent Rational Animals: Why Human Beings Need the Virtues (Peru, IL, Open Court).

Mayo, C. (2006a) Pushing the Limits of Liberalism: Queerness, Children, and the Future, Educational Theory, 56.4, pp. 469-487.

Mayo, C. (2006b) The Tolerance that Dare not Speak its Name, in: M. Boler (ed.), Democratic Dialogue in Education: Troubling Speech, Disturbing Silence (New York, Peter Lang).

Nussbaum, M. (2000) Cultivating Humanity: A Classical Defense of Reform in Liberal Education (Cambridge, Harvard University Press).

Reinders, H. (2000) The Future of the Disabled in Liberal Societies (Notre Dame, IA, Notre Dame).

Reiss, M. (1997) Teaching about Homosexuality and Heterosexuality, Journal of Moral Education, 26.3, pp. 343-352.

White, J. (2003) Five Critical Stances Towards Liberal Philosophy of Education in Britain, Journal of Philosophy of Education, 37.1, pp. 147-161. 